\title{
Design of a Technology-Oriented Bearing Assembling Cell
}

\author{
Zs. TIBA ${ }^{1}$, D. FEKETE-SZÜCS ${ }^{2}$ \\ ${ }^{1}$ University of Debrecen, Faculty of Engineering, E-mail: tiba@eng.unideb.hu \\ ${ }^{2}$ AFT Soft Ltd. E-mail: fszdani@unideb.hu
}

Keywords. stamping, finger-type feeder, dismountable construction, reversed roller, roller loss

\section{Introduction}

In this paper one of the most important process of the conical roller bearing production, the assembling is studied. Starting out from the construction feature of the conical roller bearing we will suggest the design of an automatic assembling cell having the reliability, the attainable highest productivity as the main aspect, accordingly the achievable smallest production time per piece. Our assessments apply only remotely to another bearing types, namely the construction of conical roller bearings differ from one of another bearing types.

The biggest different is the movability of the conical roller bearings in the assembling cell. It is well known that this bearing type has a dismountable construction, accordingly the outer ring and the inner assembly can be separated, moreover the bearing can come apart indeed due to not proper handling in the cell. The another significant difference is that the both of the rings of the conical roller bearing have to be stamped contrary to the single row deep grooved ball bearing in which case only the outer ring is stamped. The apparatus prescribed in the paper has been implemented and now it has been being tested. The technological parameters of the apparatus and its performance are considered confidential. However it can be stated that the performance, the reliability and the flexibility of the apparatus transcend the previous apparatuses.

\section{Assembling steps of the conical roller bearings}

For those who are not familiar with the assembling technology of the conical roller bearings we review the assembling steps briefly.

\subsection{Parts of assembled unit}

- outer ring

- inner ring 
International Journal of Engineering and Management Sciences (IJEMS) Vol. 5. (2020). No. 2

DOI: 10.21791/IJEMS.2020.2.13.

- rollers

- cage

The rings manufactured (grinded and super finished) arrives on conveyor belt to the producer cell. The finished cages and rollers are handled to the producer cell in bulk as well.

\subsection{Assembling}

Cage filling: the rollers are pressed into the cage with a special device ensuring that the rollers get to the cage with small face ahead.

Pressing: the inner ring is pressed into the filled cage. The inner ring snaps into the assembled cage due to mainly the elastic deformation of the cage, after that the assembled unit cannot be dismantled non-destructive way anymore.

Pairing: the assembled inner unit is inserted into the outer ring on the conveyor belt.

Washing: the assembled bearing is washed by paraffin oil which functions as a lubrication for the subsequent measuring.

Measurements: the bearing is rotated with a prescribed rpm and contact pressure while the bearing noise is measured based on piezo-electronic principle. Up to date measuring systems record the torque necessary for rotating. The result of measurements provides information relating to the manufacturing failures and the surface roughness. It is expedient to measure the height of the assembled bearing since this way the "reversed roller" may be realized. Measuring the mass of the bearing may give information about the roller loss.

Stamping: on the bearing ring titles, figures ID Matrix, etc. are printing. Nowadays there is an increasing need for printing different data. For this purpose, the laser printing is the most suitable can be the part of the manufacturing cell. After printing the codes are read by cameras. In the case of unsuccessful reading the bearing is classified for a waste.

Conservation: the bearing is coated with a special oil. Nowadays it is performed by oil spraying. This procedure is made after taking off the outer ring in order to reach all of the surfaces.

\section{The features of the material handling in terms of manufacturing process}

The conical roller bearing has a dismountable construction, this is why it needs a special material handling method. The bearing is either carried on the conveyor belt or slide on a table. In both cases it is expedient to place the bearing with its big face of the outer ring down. The reversing of the bearing can be performed while clamping the rings together. The following figure shows a common used reversing device: 


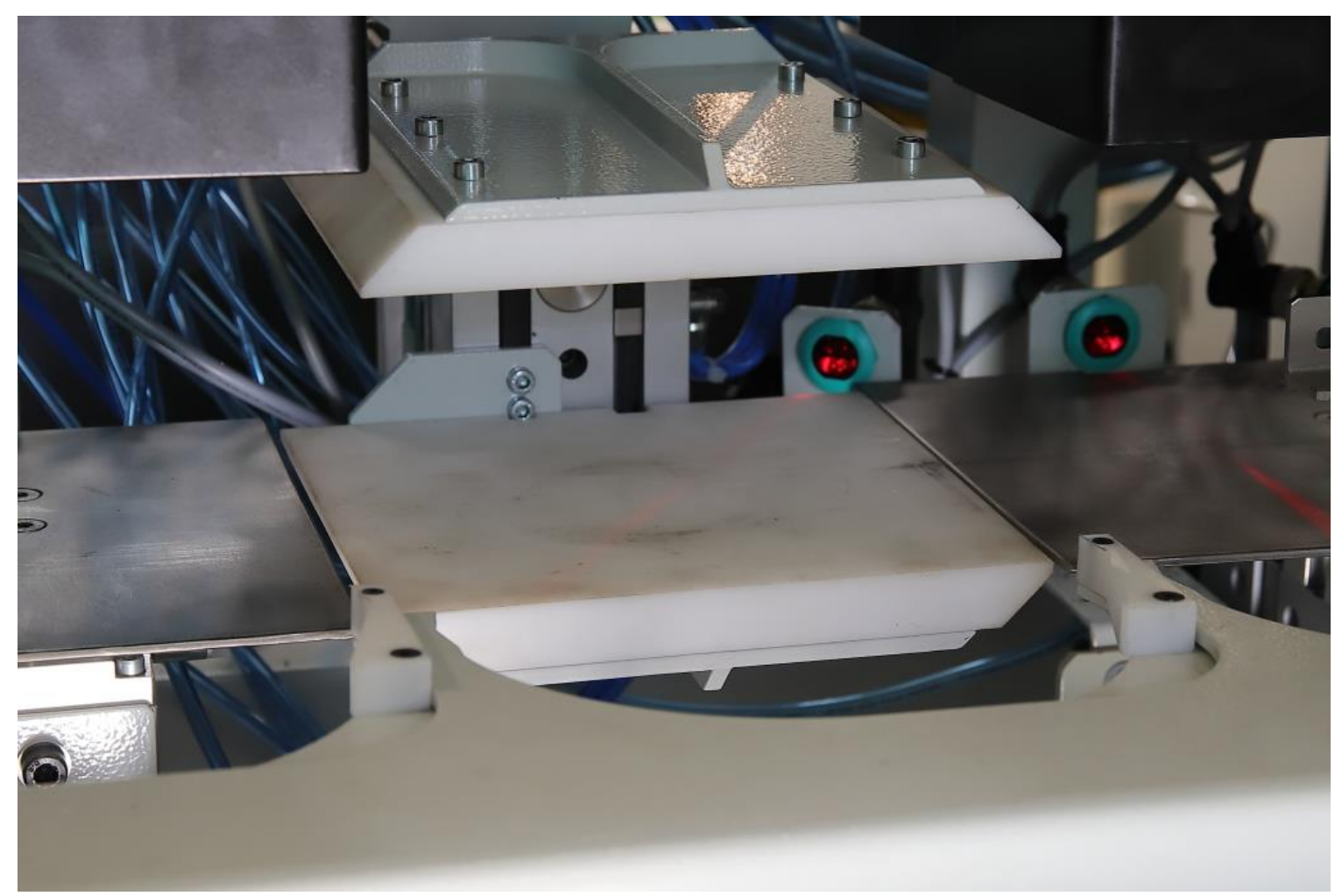

Figure 3.1 The reversing device (photo of the author)

The pneumatic reversing device contains a double shoes gripper mechanism and a rotating cylinder. After the feeding the clamper mechanism clamps the bearing, than after reversing the gripper mechanism is released.

\subsection{Feeding, the construction of the cell}

In a common assembling cell all of the assembling-measuring processes are made by a separated machine and the material handling is performed by a conveyor belt. This method is not expedient because of the following reasons:

- The space demand is big

- The conveyor is expensive

For the manufacturing the bearing has to be taken off the belt and after that it has to be pushed back which is time consuming and this is why the short time cycle cannot be provided. All the machines require the own control system, compressed air and electricity supply, which is expensive and the probability of the failure is higher. The application of the modular system is more advanced having a shared feeding. The following figure shows an example for this system. 


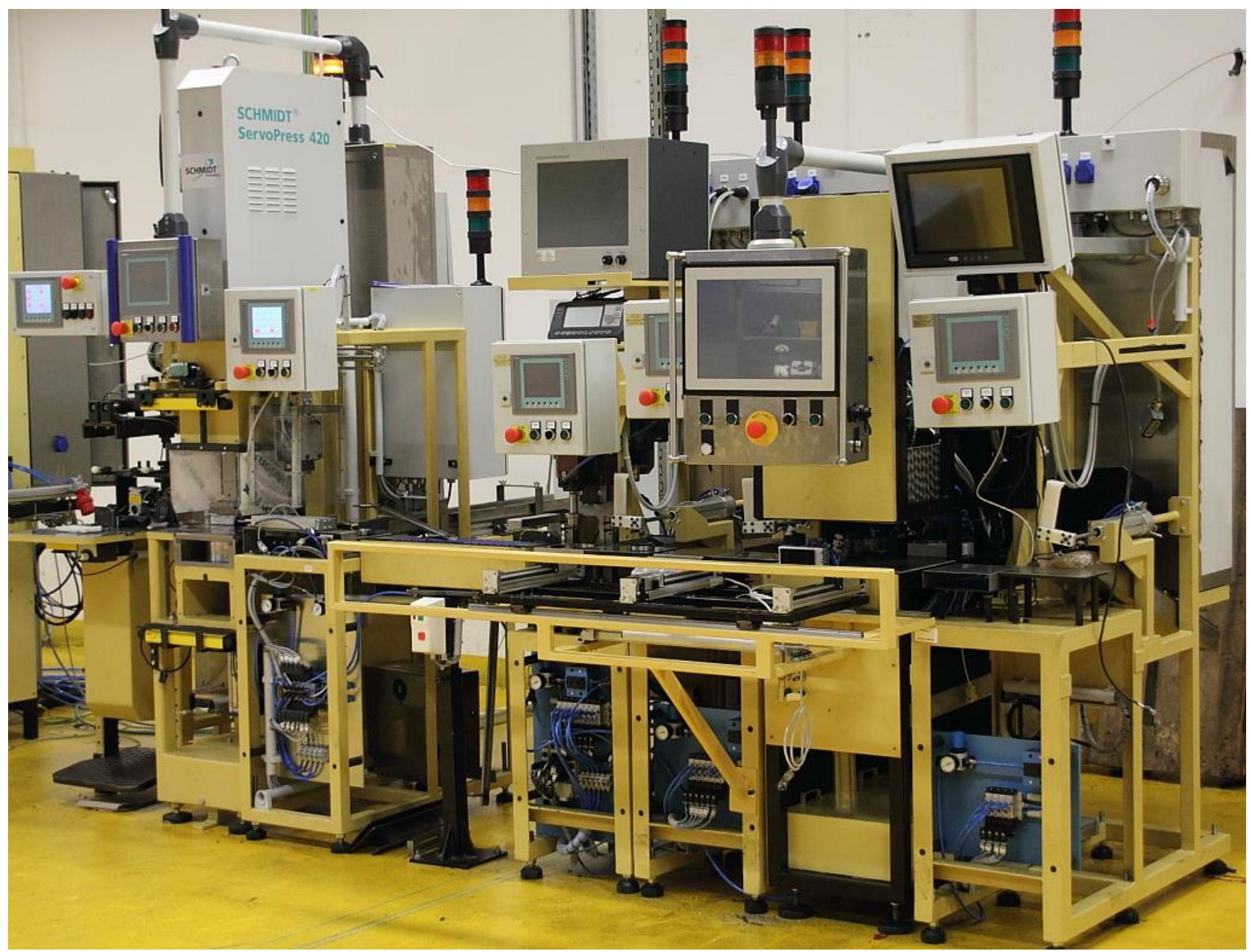

Figure 3.2 Modular assembling cell with a servo-pneumatic finger- type feeder

The construction shown in the figure provides shorter time cycle than the common one and the space demand is smaller as well. The diameter of the bearing's outer ring is differs according to its type which fact may be handled either by a servo-pneumatic or a servo-electric drive. The stroke length of them can be programmed precisely providing the positioning of the bearings on the working table. In the machine unit shown in Fig. 3.2 the first method was applied (the authors took part in its design), the feeder is operated by servo-pneumatic system. Although the apparatus is working at present too, we realized some problems:

- The servo-pneumatic linear drive (DGCI [2] having a zip-cylinder construction is prone to attrition because of the wear and damage of seals.

- The servo-pneumatic system is sensitive to the not stable air pressure. These actuators are designed for 6 bar pressure [3]. The air pressure in the actual application is less therefore it was needed to apply a pressure booster. We ignored the choice of the servo-electric actuation because of the high price of the system and the components. Eventually we designed a complicated feeder actuated by a common pneumatic system.

\section{The guiding principles of assembling cell's design}

- Here we list the design aspects to be consider:

- The possible smallest space demand

- Low implementation and operation expenses 
- Short time cycle and high productivity

- Considerable reliability

- Short change-over time

- Operating the machine won't need a skilled technician

As it may be seen, these guiding principles often contradict each other therefore the apparatus may be designed by taking compromise. A typical example for it is the laser stamper. Now we are introducing two constructions for it applied in the case of conical roller bearings where both sides have to be printed, in general on the opposite sides. The first construction applies only one laser printer. After printing one side, the bearing is turned for printing the other side. This construction is showed in Fig. 4.1.

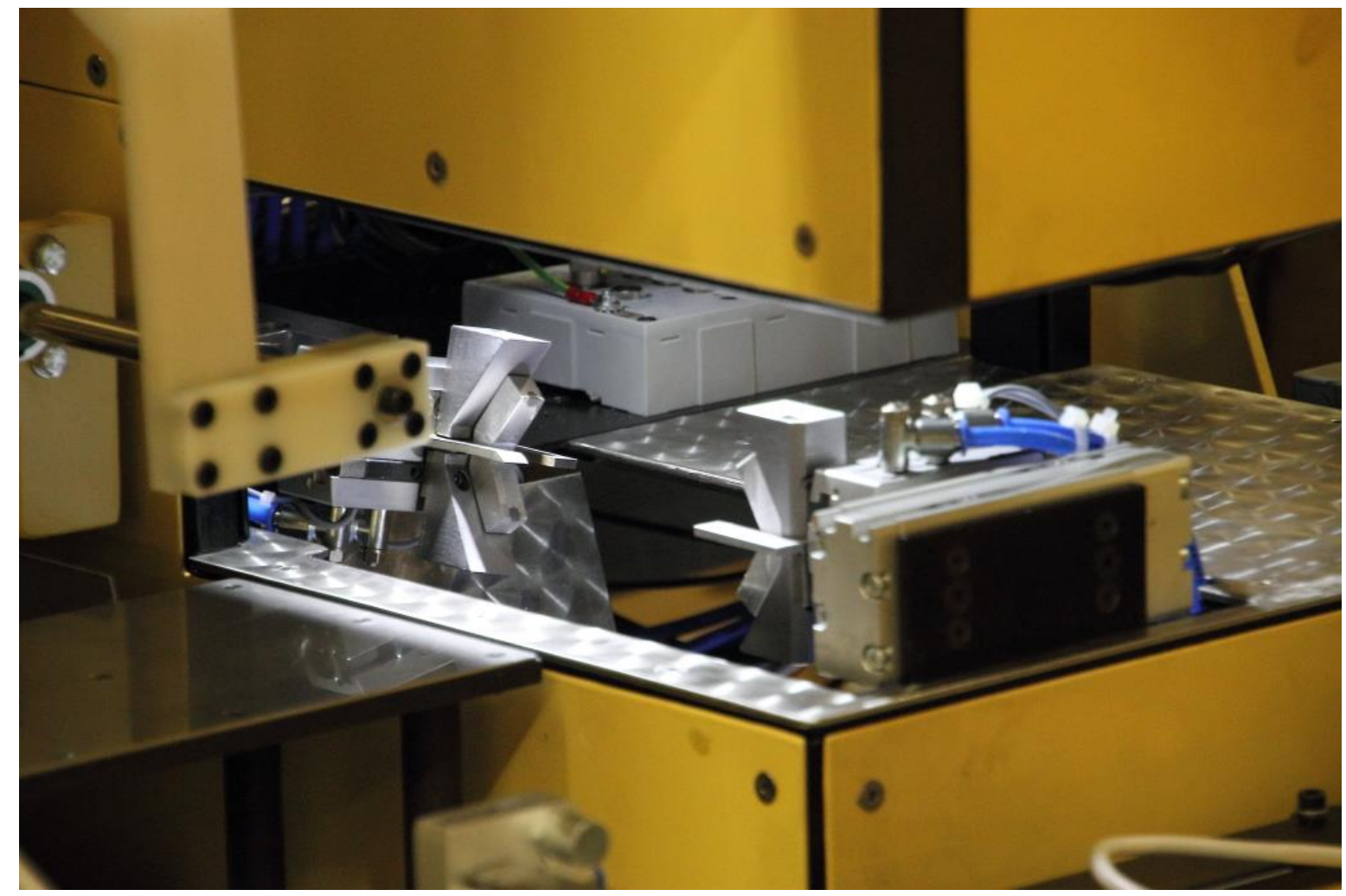

Figure 4.1 Gripping- turning mechanism of the two sided laser-stamper

In order to achieve a short time cycle, the bearing has to be fixed and turned in printing position. It requires a mechanism relatively sensitive for damage and needs regular maintenance, but its space demand is small. The investment cost is smaller since only one laser head is needed, however the time cycle is more than double compared to the two lases head system. If the time cycle of the printing is the most important consideration, one-one leaser unit is used by sides, needing bigger space and cost. The apparatus introduced in this paper has the short time cycle, high reliability and small maintenance need as a priority, this is why we choose this construction. 


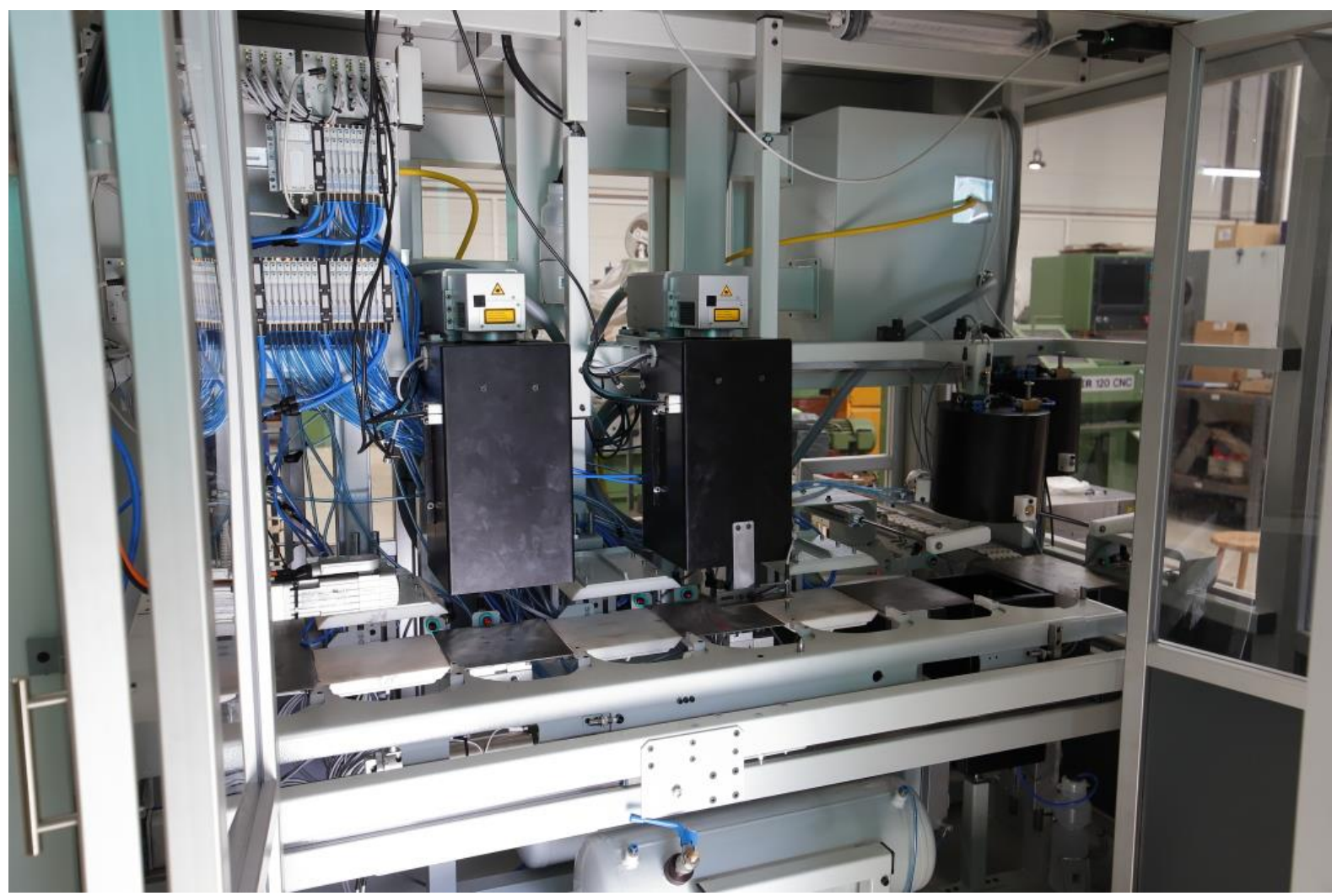

Figure 4.2 The construction of the two laser printer (photo of the author)

This construction provides shorter time cycle because the work phases may be done at the same time parallel. Although the applied mechanism is sophisticated but it is reliable and needs only regular maintenance. The applied industrial laser doesn't have auto-focus function. Therefore, the prescribed distance between the laser head and the bearing has to be kept accurately. When changing the bearing type and size, the distance has to be adjusted accordingly.

In the first construction it is performed by moving the laser head with a servo-motor mechanism. In the second construction the bearing is pushed up in a cap, like a blind hole. The bumper situated on the cap can secure the prescribed distance at any assembling height, necessary to keep the foal length of the laser. The another advantage of it is that in the case of one side construction the position of the bearing may be secured accurately during the stamping. In the construction applies the bearing turning method the printing field must be moved a little bit by a computer technic in order to correct the positioning failure of the bearing after changing the bearing type. It is not needed in the case of one side printing construction. Fig. 4.2 shows the construction of the stamping apparatus. It can be seen that it is has a much robust construction.

\section{The construction of the feeder}

As we mentioned before, there are two solutions for designing the finger-type feeder. In the first version the bearing is pushed only by one side, the different bearing ring diameters because of changing the bearing type are handled by programing the servo-pneumatic drive. The scheme of the construction is shown in the following figure. 


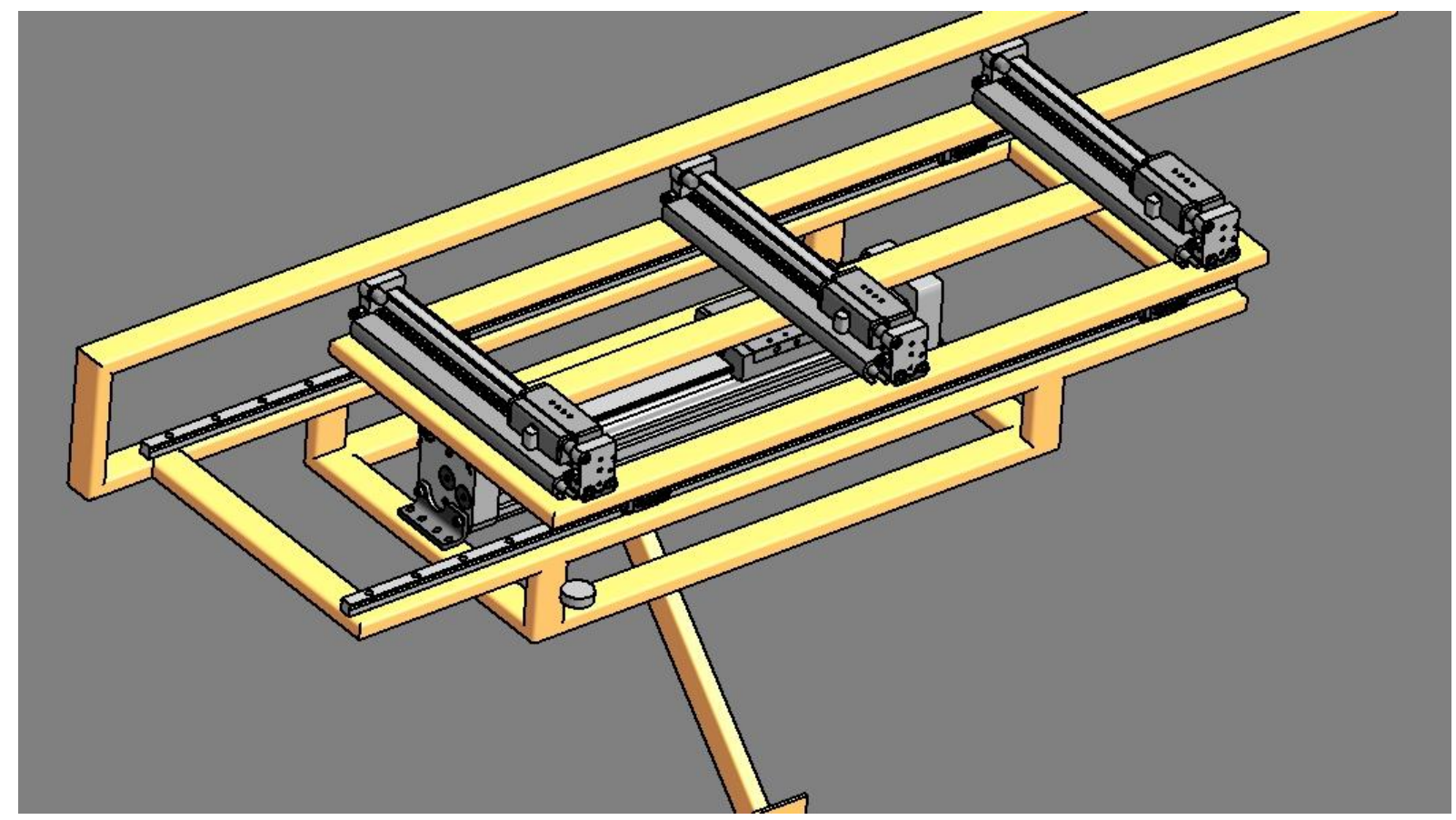

Figure 5.1 The finger-type feeder carriage saddle with the pneumatic servo [1]

As we have mentioned, the servo-pneumatic/servo-electric drive is considerably expensive, but the applied mechanism is relatively simple because of its two axes. Another solution is the application of the third carriage saddle beside the " $\mathrm{X}$ " and "Y" axes, moving the two finger-type arms synchronized. The operation method of the mechanism can be seen in the following figure.

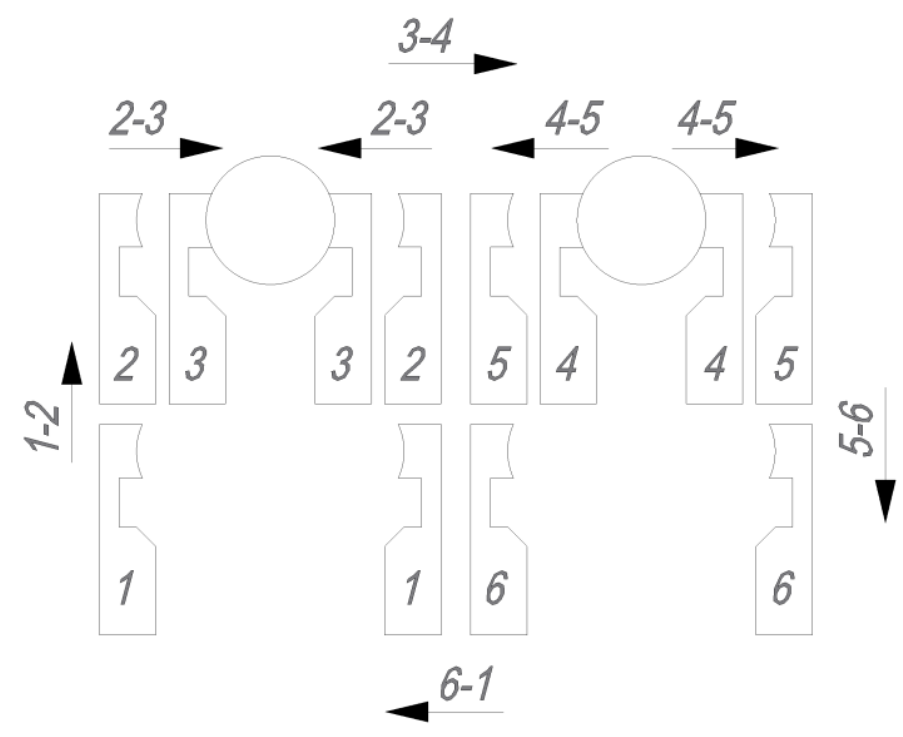

Figure 5.2 The principal scheme of the moving of the common three axis finger-type feeder

(The figure represents only an arm-pair, the number of arm-pairs is less by one than the number of terminals)

The construction of the feeder can be seen in Fig. 4.2. Its advantage is, that it can be operated with pneumatic cylinders. The synchronous moving of the cylinders is provided by FESTO HGPL [2] parallel 
gripper. The mashing gear and rack built in the gripper provides the positioning of the bearing may have different diameters in the stroke range. It is very important that the change of bearing type doesn't require any other corrective action. The mechanical analysis of the feeder was performed with the application of "pneumatic and dynamic simulation" software [4]. In this paper we dispense with publishing the details of calculation because of extend limitation.

\section{Stressing the mechanism of the finger-type feeder}

Because of the volume limitation we dispense with the explaining the strength and the dynamic analysis of the whole apparatus. As an example we show the stressing of the mechanism of the fingertype feeder. A detail of the arm of the upper finger-type feeder is shown in the following figure.

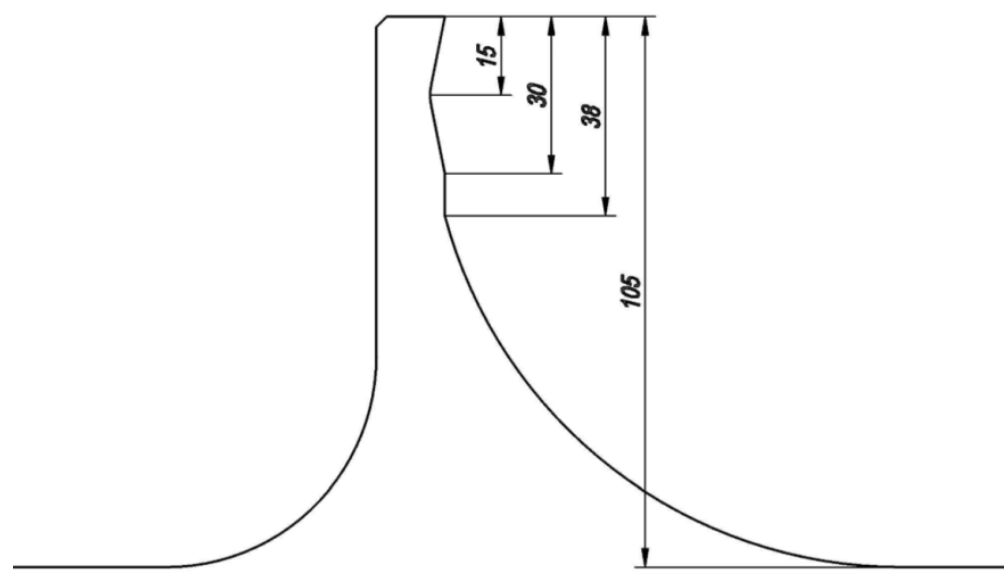

Figure 6.1 The arm of the finger-type feeder

The load of the arm is shear and bending. The stress resulting from the shear is determined by common strength analysis and the we give the average stress. The maximum stress resulting from the bending is calculated accurately. Due to the small acceleration of the mechanism, we consider the quasi static load and disregard the mass forces. The critical cross section of the arm is the middle of the prism positioned from $15 \mathrm{~mm}$ distance from the peak. Data not shown in the figure:

cross section area: $4 * 8=32\left[\mathrm{~mm}^{2}\right]$

the distance of the critical cross section from the action line of the motion force $\mathrm{k}=157 \mathrm{~mm}$

the feeder is used on max. 4 bar pressure, the diameter of the pneumatic cylinder of the double shoe HGPL megfogó: d=25 mm.

The load: $\mathrm{F}=\mathrm{p} * \mathrm{~A}=\mathrm{p}^{*} \mathrm{~d}^{2} \pi / 4=4 * 10^{5} \mathrm{~Pa} * 490.6 \mathrm{~mm}^{2}=196.24 \mathrm{~N}$; 
The material of the finger-type feeder: S355, its yield point: $\mathrm{R}_{\mathrm{eH}}=355 \mathrm{MPa}$.

The shear stress: $\tau=F / A_{k}=196.24 \mathrm{~N} / 32 \mathrm{~mm}^{2}=6.13 \mathrm{MPa}$.

The bending moment: $\mathrm{M}_{\mathrm{h}}=\mathrm{F}^{*} \mathrm{k}=196.24 \mathrm{~N} * 157 \mathrm{~mm}=30.809 \mathrm{Nmm}$.

The normal stress resulting from the bending:

$\sigma_{\max }=\mathrm{M}_{\mathrm{h}} / \mathrm{K}_{\mathrm{x}}=\mathrm{M}_{\mathrm{h}} /\left(\mathrm{a}^{*} \mathrm{~b}^{2} / 6\right)=30.809 \mathrm{Nmm} / 21.33 \mathrm{~mm}^{3}=1.444 \mathrm{MPa}$;

The resultant stress: $\sigma_{\text {red }}=\left(\sigma_{\max ^{2}}+3 * \tau^{2}\right)^{1 / 2}=10.714 \mathrm{MPa}$;

The factor of safety: $\mathrm{n}=\mathrm{R}_{\mathrm{eH}} / \sigma_{\text {red }}=355 \mathrm{MPa} / 10.714 \mathrm{MPa}=10.71$.

It can be seen that the finger-type feeder is overstressed due to its robust construction.

\section{Technology-oriented design, flexibility, switch-over}

The apparatus is eligible for stamping, reading data, weighting and conversation. According to the assessment of our client, the technology processes before the stamping can be made with machines have been at disposal (see chapter 2). Therefore, we designed the apparatus to be appropriate for flexible extension with the pairing, washing, noise measuring. Further apparatuses may be implemented in the extended configuration. In this apparatus the cage filling will be made with a semiautomatic machine requiring an operator continuously. The feeding is made by one by one material flow that is not up-to-date way. Therefore, we suggested a tunnel washer to be installed in front of the noise measurement and that the conveyor should have the function as a work piece puffer too. This way the operation of the cell will be steady.

As we mentioned before, the we chose the two laser construction. The build-up of the apparatus is "FEEDING-TURNS-TAMPING-TURN-STAMPING-WASTE PRODUCT REMOVING-CONSRVATIONFEEDING OUT". Independently of the position of the bearing arriving in the apparatus, any of the stamping can be performed with the turning mechanisms. This way the stamping may be performed in any sequence based on the data content of it in both cases: one side and both sides stamping process. The conservation technology requires that the bearing arrives to the conservation unit with the big face down of its inner ring since the outer ring can be lifted off for the conservation process. It can be performed with turning mechanisms installed between and after the stations without time loss. The stoke length of the pneumatic cylinders are determined to be able to handle the different bearing sizes, so we don't need "small bearing" or "big bearing " units. In terms of machine design this flexibility is a very big advantage. An important technology directive is that waste product cannot get to the next station. The applied technology fulfils this requirement since the bearings have been assembled and checked before stamping. (The acid stamping technology can be applied only for bearing rings before assembling).

The switch-over from one bearing size to the other one is rather simple. The system adjusts the stamping contents, the manufacturing mode and the necessary dimensions automatically. The only one manual manipulation is the change of the arm of the catcher mechanism in the conservation unit 
lifting off the outer ring of the bearing. The change is necessary because the stroke length of the catcher mechanism is not appropriate for the whole diameter interval.

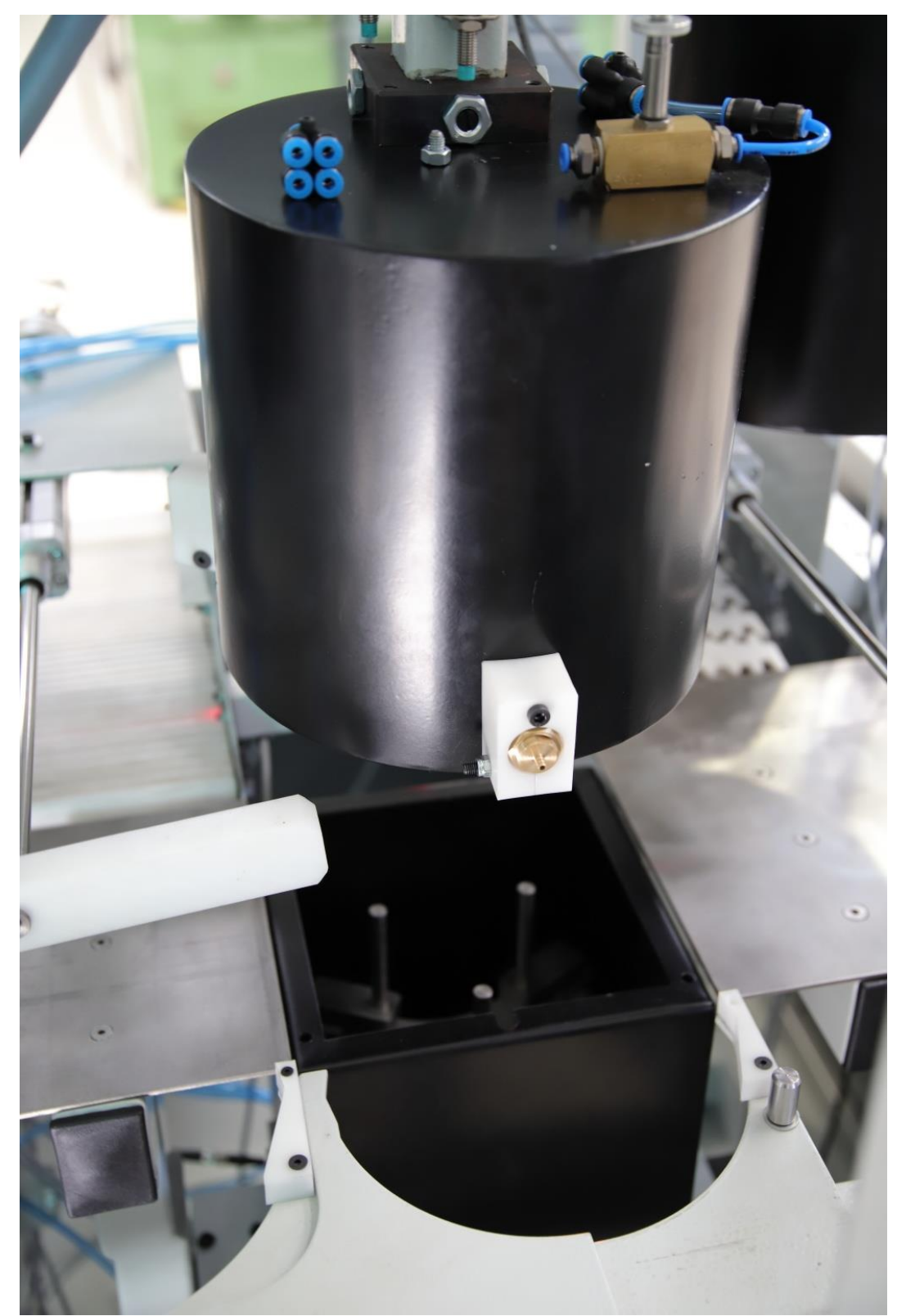

Figure 7.1 The build-up of the conservation unit [ photo of the author]

\section{Technics of security}

The design of the apparatus is in conformity of the directives set forth in the standard [5], namely the operators have to be protected by a triple level system against the possible dangers (mechanical, electrical and computer software). The apparatus is implemented with a closed casing, automatized operation and manual handling can be made only with closed doors. The laser units are instrumented with own sensors providing the safe operation when the laser units are closed. All of the security sensors are connected into a special security module so ignoring the security measures are not 
possible. However, the casing is made of transparent polycarbonate therefore the operation of the apparatus can be surveyed, controlled.

\section{Summary}

This paper contains neither the description of the programming of the apparatus and its integration into the information system of the company, nor the self-diagnostic and the remote supervisory system. In the design the flexibility and the big productivity had the priority; the cost and the dimensions were not important. We hope, in this paper it can be realized how these directives were applied in the practice.

\section{References}

[1] Darai Sándor: Lézer-bélyegző és cella-adagoló tervezése. Debreceni Egyetem Műszaki Kar, 2013.

[2] Cadenas GmbH: Part Data Manager v11.00, Augsburg, 2017.

[3] FESTO GmbH: Documentation for linear drives with DGCI displacement encoder. www.festo.com, 2017

[4] FESTO GmbH: Handling Guide and Simulation. www.festo.com, 2018.

[5] Nemzetközi Szabványügyi Hivatal: Gépek biztonsága. MSZ EN ISO 12100:2011. 